\title{
Katherine Ashley, Edmond de Goncourt and the Novel: Naturalism and Decadence
}

\section{Nicola Ferrari}

\section{(2) OpenEdition}

1 Journals

\section{Edizione digitale}

URL: http://journals.openedition.org/studifrancesi/30673

DOI: 10.4000/studifrancesi.30673

ISSN: 2421-5856

\section{Editore}

Rosenberg \& Sellier

\section{Edizione cartacea}

Data di pubblicazione: 1 avril 2006

Paginazione: 188

ISSN: 0039-2944

\section{Notizia bibliografica digitale}

Nicola Ferrari, «Katherine Ashley, Edmond de Goncourt and the Novel: Naturalism and Decadence», Studi Francesi [Online], 148 (XLX | I) | 2006, online dal 30 novembre 2015, consultato il 22 avril 2021. URL: http://journals.openedition.org/studifrancesi/30673; DOI: https://doi.org/10.4000/studifrancesi. 30673

Questo documento è stato generato automaticamente il 22 avril 2021.

\section{(c)}

Studi Francesi è distribuita con Licenza Creative Commons Attribuzione - Non commerciale - Non opere derivate 4.0 Internazionale. 


\title{
Katherine Ashley, Edmond de Goncourt and the Novel: Naturalism and Decadence
}

\author{
Nicola Ferrari
}

\section{NOTIZIA}

KATHERINE ASHLEY, Edmond de Goncourt and the Novel: Naturalism and Decadence, Amsterdam-New York, Rodopi, 2005, 253 pp.

Dopo la morte nel 1870 del fratello Jules, a Edmond de Goncourt rimangono ancora ventisei anni per proseguire l'avventura letteraria intrapresa con il suo (fino ad allora) indissolubile sodale di scrittura : anni cruciali nei quali l'ideale naturalistico si ritira progressivamente sotto l'ondata estetizzante del Decadentismo. Di questa svolta poetica fin-de-siècle, della interna deformazione prospettica (anamorfica?) imposta alla concezione documentaria del testo (così come era stata elaborata congiuntamente dai fratelli Goncourt) i quattro romanzi in solo di Edmond (e specialmente gli ultimi tre) costituirebbero una delle più cruciali testimonianze - la vocazionale rivendicazione di una trasparenza rappresentativa del linguaggio travolta dal pieno fallimento della sua istanza comunicativa. Misurando la distanza che separa la produzione a quattro mani (precedente il 1870), da quella solistica successiva, la tesi di Ashley su questa rivelativa embricatura di Naturalismo e Decadentismo si dimostra nei testi (con un'analisi narratologica di chiara impronta genettiana) a differenti livelli. Paratestualmente: i titoli eponimi (costante stilistica della produzione dei Goncourt) tendono progressivamente (in Edmond) a far slittare la focalizzazione individuale dal piano delle categorizzazioni sociali (o comportamentali) a quella delle identità non tipicizzabili; le nuove prefazioni attestano ai romanzi un'originalità che impedisce loro di essere pianamente (e pienamente) sussunti entro i precedenti schemi programmatici - che pure rimangono confermati sul piano teoretico. Se l'istanza documentaria dell'impianto naturalista continua ad essere preservata e integrata nella finzione 
romanzesca, la scelta (decadente) dell'oggetto da documentare trascina la narrazione verso il regno dello sconosciuto e dell'inverificabile - fino ad un'eccentricità digressiva che neghi la teleologia romanzesca: la trama si frammenta, l'evenemenzialità si scompone, si indeboliscono le catene causali, la poesis soppianta la mimesis, si descrive più di quanto si narri, la progressione attraverso il tempo risulta funzione del processo di lettura più che dello sviluppo di intrigo. Nello specchio interno degli scambi linguistici tra i personaggi, la comunicazione letteraria esibisce il depotenziamento della propria funzione transazionale: votato all'impotenza, il discorso diretto gira a vuoto, si (di)mostra strumento di immobilizzazione della trama, decostruzione della struttura formale del romanzo, di attrazione ineludibile per l'annichilimento del silenzio. Persino la scelta (ideologicamente naturalistica) di lessici specifici e differenziati vira verso un compiacimento (ancora decadente), una gustata contemplazione della sonorità di significanti - elusivi ed enigmatici nel loro significato proprio. Da Les Frères Zemganno (nell'ondeggiamento irrisolto tra fatto e finzione, i dettagli finalizzati alla verosimiglianza dell'ambientazione invertono il loro segno programmatico finendo con il rappresentare un luogo fatalmente simbolico nella sua inafferrabile, ingannevole illusorietà) attraverso La Faustin (insieme al trascendimento di un quadro storico determinato, il tema elettivamente naturalista dell'ereditarietà subisce una metamorfosi estetizzante) fino a Chérie (giuoco avanguardisticamente ipertestuale condotto a delegittimare la funzione strutturante della trama: il document humaine si rivela puro decorativismo), i tre ultimi romanzi di Edmond de Goncourt rivelano convincentemente alla lettura critica di Ashley una loro natura ambiguamente sospesa (tra volontà e realizzazione, passato e futuro) rispetto ai programmi che si spartiscono l'immaginazione letteraria della fine secolo. Manca però a questa indagine fenomenologica un'interrogazione teorica sulle ragioni di una tale sovrapponibilità nell'opera - e non solo di Goncourt - di programmi poetici che si pongono antinomicamente contrapposti tanto nelle intenzioni che nelle tecniche di rappresentazione. 